\title{
Субботина И.Ю.
}

\section{Совершенствование социально-трудовых отношений посредством формирования инструментария развития трудовых ресурсов системы «человек-производство»}

\author{
Subbotina I.Yu. \\ Improvement of the social and labor relations by means \\ of formation of tools of development of a manpower \\ of the person production system
}

В статье рассматривается модель взаимодействия элементов формирования трудовых ресурсов и две основные методики оценки персонала предприятий способствующие развитию социально-трудовых отношений Ключевые слова: социально-трудовые отношения, трудовые ресурсы, кадровая стратегия

\section{Субботина Ирина Юрьевна}

Кандидат экономических наук, заведующий кафедрой

Московский технологический университет Шахтинский филиал

г. Шахты, пр. Карла Маркса, 110
In article the model of interaction of elements of formation of a manpower and two main techniques of performance appraisal of the enterprises promoting development of the social and labor relations is considered

Key words: social and labor relations, manpower, personnel strategy

\section{Subbotina Irina Yurievna}

Candidate of Economic Sciences, Head of

Department

Moscow technological university Shakhty branch

Shakhty, Karl Marx ave., 110

Эффективное развитие социально-трудовых отношений в системе «человек-производство» осуществляется на основе прогрессивной кадровой политики и детализированной кадровой стратегии, а также взаимосвязи между бизнес-стратегией организации, стратегией формирования и развития персонала. Эти направления взаимообусловлены и логично дополняют друг друга, что позволяет сделать управление более эффективным. Оценка эффективности данных инструментов реализована посредством принципов, основными из которых являются:

- практичность - определение направлений карьерного роста для различных категорий персонала, методов мотивации;

- направленность - определение ориентиров для достижения целей, а также формирование эффективного гудвилла организации на рынке с целью привлечения трудовых ресурсов;

- своевременность - внутреннее обучение, создание кадрового резерва; 
- действенность - соответствие разработанной кадровой политики реальным методам управления, т.е. ориентированность на результат предпринятых действий.

Развитие системы «человек-производство» посредством приращения социально-трудовых отношений является многоплановым процессом, реализующимся путем использования следующего инструментария: оценка персонала, проведение аттестации и сертификации, разработка положений о корпоративной культуре, мониторинг рынка труда, анализ эффективности деятельности персонала, прогнозирование потребности в персонале, психодиагностика, формирование эффективной системы мотивации, ротация персонала, кадровый и мотивационный аудит.

Актуальным является развитие профессионального потенциала сотрудников и достижение с их помощью максимальных результатов деятельности. В рамках кадровой политики это означает акцентирование внимания на таких направлениях формирования и развития социально-трудовых отношений с целью укрепления кадрового потенциала, как: мотивация саморазвития и результативности, грейдирование, разработка и реализация программ развития, оценка компетентностного уровня специалистов и их результативности, выявление наиболее эффективных специалистов; управление карьерой, формирование интеллектуального капитала организации.

Для достижения поставленных целей и решения вышеперечисленных задач была сформирована система работы с персоналом, которая позволила объединить все процессы формирования трудовых ресурсов (рисунок 1).

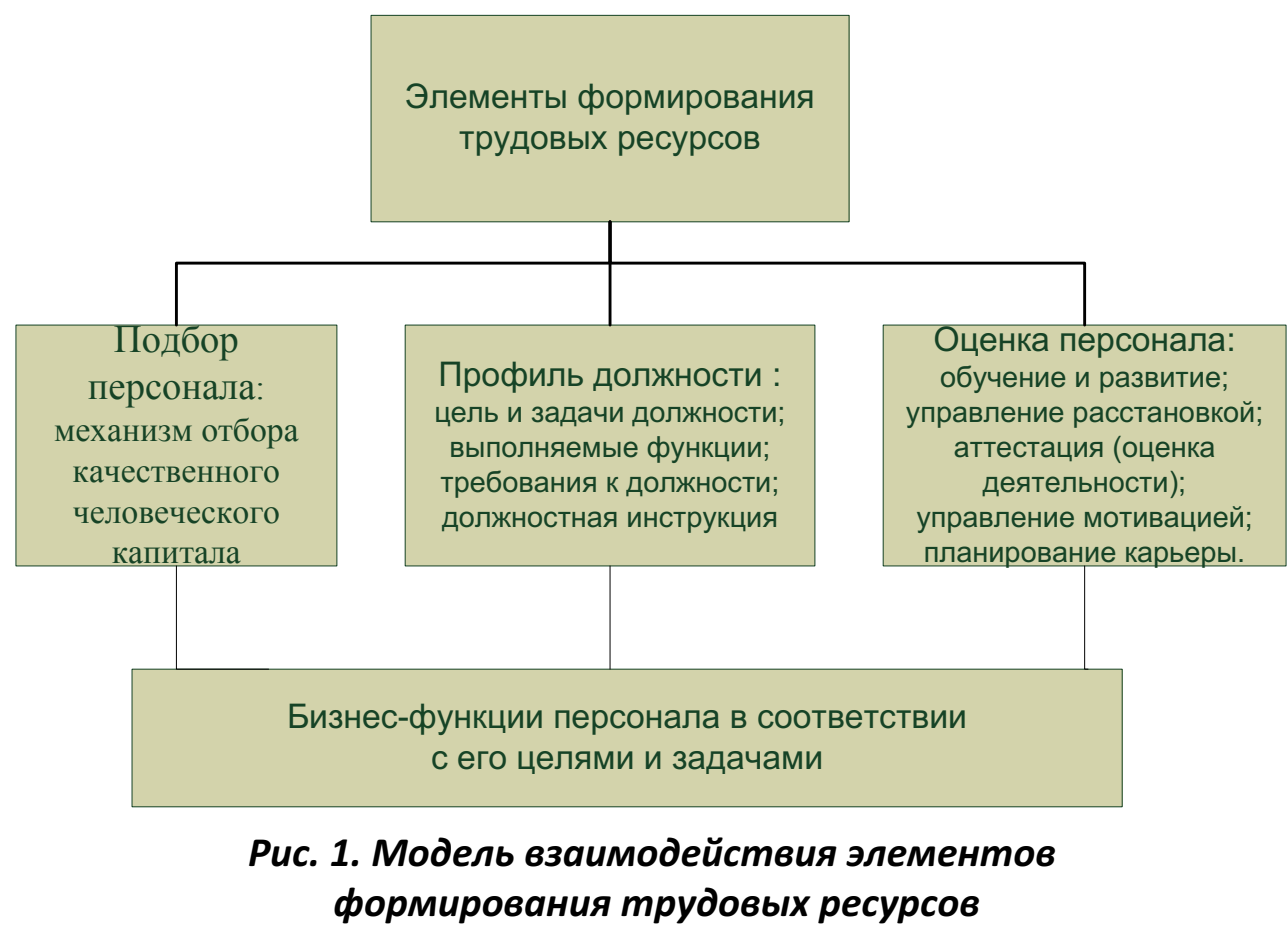

В этой модели все процессы разделены на 3 группы: процессы, целью которых является формирование трудовых ресурсов в соответствии с профилем должности; процессы, фиксирующие все данные о персонале, необходимые для 
формирования и развития социально-трудовых отношений в организации; процессы, определяющие параметры, необходимые для обеспечения организации трудовыми ресурсами.

Для формирования адекватной кадровой политики на предприятиях необходимо выполнить следующие условия:

а) во-первых, все процессы, связанные с формированием и развитием социально-трудовых отношений, выстраиваются как регулярная, регламентированная деятельность, т.е. по каждому процессу установлены правила и процедуры, выделены и определены точки контроля, разработаны показатели оценки эффективности функционирования и сформирована отчетность;

б) во-вторых, автоматизированы данные процессы с целью получения необходимой информации.

Для поддержания единого процесса и эффективного развития социальнотрудовых отношений в рамках формирования трудовых ресурсов на предприятиях должна быть выстроена информационная система. Она предоставляет руководителю возможности:

- анализа и контроля затрат в сфере кадровой работы, а также оценки их эффективности;

- мониторинга показателей эффективной работы с трудовыми ресурсами в организации;

- снижения рисков при принятии кадровых решений на основе экономико-математического моделирования, позволяющего заранее спрогнозировать последствия управленческих действий.

Информационная система развития трудовых ресурсов обеспечивает прозрачность и доступность данных персонала предприятия, позволяет своевременно принимать необходимые кадровые решения, а также осуществлять перестановку и назначать специалистов на соответствующие должности. При этом использование информационных систем способствует снижению затрат на обучение персонала, увеличивает скорость их подготовки, передачи корпоративных знаний и технологий.

Автоматизация кадровой политики предоставляет ряд преимуществ, информационно обеспечивая сквозные бизнес-процессы и процессы принятия кадровых решений в сфере формирования и развития социально-трудовых отношений. Сбор и хранение базы данных о сотрудниках, их квалификации и истории работы на предприятии позволяет эффективно управлять кадровым потенциалом; создание корпоративных баз знаний, корпоративных правил и регламентов, наработанных методик и инструментов дает возможность оперативно ознакомить с ними новых сотрудников, способствует взаимному обучению и обмену опытом, а также снижает риск потери информации при увольнении сотрудников из организации; способствует формированию данных для принятия кадровых решений.

К преимуществам, которые предоставляет организации автоматизация кадровой работы, относят экономию времени на выполнение оперативных задач и повышение эффективности деятельности. 
Формирование социально-трудовых отношений и развитие трудовых ресурсов организации - это трудоемкий процесс, эффективность которого заключается в том, чтобы обеспечить раскрытие и использование потенциала каждого специалиста для достижения долгосрочных целей организации с учетом располагаемых ресурсов. Организация данного процесса как элемента общей системы управления хозяйствующим субъектом и обеспечение его необходимой информацией должны стать приоритетом развития предприятия.

В целях обеспечения эффективной кадровой работы и наращивания интеллектуального капитала на стадии отбора персонала предприятие осуществляет подбор и аттестацию кандидатов. Специалист по подбору персонала еще до начала собеседования с кандидатом составляет детальный план того, какие инструменты и методы необходимы для получения информации, требуемой для оценки по каждой разработанной компетенции. Общий перечень инструментов и методов, используемых при собеседовании, включает:

1. Анализ конкретных ситуаций исходя из опыта кандидата или заданных специалистом.

2. Опрос кандидата с использованием открытых вопросов и построением из логических цепочек.

3. Использование проективных вопросов.

4. Встраивание в собеседование письменных упражнений, тестов.

5. Применение провокационных приемов.

6. Расширение списка рекомендателей и проверка отзывов.

7. Анализ речи соискателя и невербального поведения на собеседовании, а также выявление метапрограмм поведения.

8. Оценка соискателя по задаваемым им самим вопросам.

Данные подходы необязательны к применению в каждом конкретном случае. Набор инструментов и методов определяется исходя из необходимого объема оцениваемых компетенций с учетом профессиональных характеристик специалиста.

В процессе отбора кандидата на соответствующую должность возможно использование различных методик. Применительно к российским предприятиям рассмотрены и проанализированы две методики: STAR и ABC-анализ.

Схема STAR состоит из четырех этапов (S - ситуация; T - цель, трудности и проблемы ситуации; A - действия; $\mathrm{R}$ - результаты и последствия действий, изменение ситуации) и позволяет получить достоверную информацию о соискателе.

Возможность применения данной технологии актуальна в том случае, если соискатель заинтересован в рассматриваемой должности и организации в целом. При этом, чем выше его заинтересованность в работе, тем более детален план собеседования и глубже вопросы. Стиль общения с соискателем - располагающий, что позволяет легче получить необходимую для оценки информацию и заинтересовать его. При оценке степени заинтересованности соискателя и выбора соответствующего стиля общения, собеседование начинается с выявления его мотивации. Оценка результатов собеседования осуществляется по выявленным мотивам и компетенциям, которыми владеет соискатель. 
В процессе анализа ситуации и использования других приемов оценки накапливается информация (плюсы или минусы) по рассматриваемой компетенции и связанным другим компетенциям соискателя. Данная информация отражается в свободной форме и используется при подготовке структурированного заключения по компетенциям в дальнейшем. Список компетенций определяется заранее, что позволяет специалисту по кадрам не упустить необходимые компетенции при проведении оценки. Получение достаточного объема информации для проведения оценки по определенной компетенции позволяет отметить данную компетенцию в списке как изученную, и работа продолжается по другим компетенциям. Если в ходе собеседования выясняется несоответствие соискателя по одной или нескольким компетенциям требованиям и профилю должности, то при отсутствии иных целей собеседование с соискателем прекращается, что позволяет сэкономить на затратах при оценке кандидатов по компетенциям.

Структурированное заключение по компетенциям представляется как перечень профессиональных и личных компетенций, в котором отражена количественная оценка соответствия соискателя требованиям и профилю должности по каждой из них. При этом используется следующая шкала оценок:

1 - полное несоответствие соискателя требованиям и профилю должности. Компетенция выражена слабо и недостаток знаний и умений не может быть компенсирован за счет других компетенций или возможным обучением;

2 - частичное несоответствие требованиям и профилю должности, которое может быть компенсировано за счет уровня профессионализма по смежным компетенциям;

3 - полное соответствие требованиям и профилю должности;

4 - качества соискателя по данной компетенции более развиты, чем этого требуется в соответствии с требованиями и профилем должности;

5 - особо высокие показатели соискателя по данной компетенции.

Если соискатель имеет по отдельным компетенциям оценку 1, то он не рассматривается как рекомендуемый на соответствующую должность, за исключением, если длительный поиск кандидатов соответствующей квалификации не дал требуемых результатов. В этом случае предприятие корректирует требования к должности, и ранее отклоненный кандидат может претендовать на должность по скорректированным требованиям.

Наивысшая оценка теоретически возможна, но на практике используется крайне редко. Если у соискателя по ряду компетенций оценки 4, то возможно он рассматривается в качестве претендента на более высокую должность, поэтому необходимо более тщательно анализировать мотивы соискателя с тем, чтобы оценить его заинтересованность именно в данной работе.

Другой методикой оценки персонала, адаптированной к российским предприятиям, является ABC-анализ. Данная методика основывается на:

- определении личных характеристик, необходимых для соответствующей должности и квалификации;

- оценке профессиональных требований к квалификации и анализе достижимости определенных показателей; 
- выборе ключевых показателей деятельности для оцениваемой должноСТИ;

- выборе метода сбора данных и порядка получения результатов оценки.

Оценка соискателей посредством данной методики реализована в двух разрезах: личные и профессиональные качества. ABC-анализ эффективен при принятии кадровых решений о квалифицированном составе работников, а также при планировании их дальнейшего обучения, определения профессионального потенциала или анализа результатов их саморазвития в долгосрочном периоде.

Таблица 1. Сравнительная характеристика данных методик

\begin{tabular}{|c|c|}
\hline Схема STAR & АВС-анализ \\
\hline \multicolumn{2}{|c|}{ ПРЕИМУЩЕСТВА } \\
\hline $\begin{array}{l}\text { - накопление информации по всем компе- } \\
\text { тенциям персонала; } \\
\text { - экономия затрат при оценке компетен- } \\
\text { ций }\end{array}$ & $\begin{array}{l}\text { - дифференциация компетенций для кон- } \\
\text { кретных должности и квалификации; } \\
\text { - оценка проводится по личным и профес- } \\
\text { сиональным качествам соискателя; } \\
\text { - позволяет оценить персонал как пред- } \\
\text { приятия в целом, так и его отдельных под- } \\
\text { разделений }\end{array}$ \\
\hline \multicolumn{2}{|c|}{ НЕДОСТАТКИ } \\
\hline $\begin{array}{l}\text { - эффективна только если соискатель за- } \\
\text { интересован в должности; } \\
\text { - требует большой подготовительной ра- } \\
\text { боты; } \\
\text { - дает усредненную оценку компетенций } \\
\text { персонала }\end{array}$ & $\begin{array}{l}\text { - требует дополнительных затрат на обу- } \\
\text { чение оценщиков; } \\
\text { - большая трудоемкость работ }\end{array}$ \\
\hline
\end{tabular}

Применение $\mathrm{ABC}$-анализа на предприятиях позволит организовать оценку труда соискателя на должность, а также конкретного работника организации и добиться соответствия индивидуальных профессиональных возможностей и производственных потребностей, а также учитывать сильные и слабые стороны каждого из соискателей на соответствующую должность.

(C) 2016, Субботина И.Ю.

Совершенствование социально-трудовых отношений посредством формирования инструментария развития трудовых ресурсов системы «человек-производство»
(C) 2016, Subbotina I.Yu. Improvement of the social and labor relations by means of formation of tools of development of a manpower of the person production system 